\title{
What Do Project Managers Actually Do? Exploring Micro-Practices of Managing Temporary Organizational Forms
}

\author{
Bart Cambré ${ }^{1}$, Jeroen de Jong ${ }^{2}$ \\ ${ }^{1}$ Antwerp Management School, Antwerp, Belgium; ${ }^{2}$ Department of Organization Studies, Tilburg University, Tilburg, The Netherlands. \\ Email: bart.cambre@ams.ac.be, j.p.dejong@uvt.nl
}

Received February $24^{\text {th }}, 2013$; revised March $28^{\text {th }}, 2013$; accepted April $28^{\text {th }}, 2013$

Copyright (C) 2013 Bart Cambré, Jeroen de Jong. This is an open access article distributed under the Creative Commons Attribution License, which permits unrestricted use, distribution, and reproduction in any medium, provided the original work is properly cited.

\begin{abstract}
While the management of projects is rapidly gaining importance in the current fast pace economy, there is a growing dissatisfaction with its theoretical underpinnings. Rooted in an exploratory micro-analysis of the practices of 86 project managers, our study demonstrates that project managers engage in 10 core practices, which together imply that managing projects 1) is only partly about planning and scheduling, 2) is locally situated in specific types of projects, 3) is an activity aimed at a continuous recoupling of diverse practices, and 4) is shaped by project contexts, which act as temporary points of intersection for social practice. Together, we propose these practices form a set of building blocks for a practice-perspective of project-based organization, presenting an alternative to the theoretical paradigm currently dominating the field.
\end{abstract}

Keywords: Management Practice; Project-Based Organization; Project Management; Strategy-as-Practice; Temporary Organization

\section{Introduction}

As more and more industries look for flexible ways of production in the wake of rapidly changing market environments, organization in the form of short-term projects is becoming increasingly important in the current economic landscape $[1,2]$. Stemming from its roots in engineering, however, there has arisen recently among organization scholars a growing discomfort with a number of theoretical assumptions present in project research (e.g. [3-5]). These assumptions concern, for instance, the role of the project manager as a planner and scheduler and the assumption that a project can be regarded as a tool, and is as such highly moldable and transparent [5]. Recent research on projects, however, considers a project as "a set of organizational actors working together on a complex task over a limited period of time" [1], or temporary organizational forms $[1,6]$. This perspective on projects also makes forceful claims about project management, including a primary concern with people rather than tasks, descriptive rather than prescriptive theory [5], and the consideration of relations with the organizational and social context in which the project is embedded [4].
Building on this new perspective on projects, our study is based on an empirical analysis of the practices of 86 project managers and the way these form a micro-explanation for what the management of temporary organizational forms is about. We formulated the following research question to guide this study: Which practices do project managers use in daily practice, how do these relate to different kinds of project contingency factors, and how do they inform our understanding of project-based organization? As such, this endeavour is informed by the strategy-as-practice perspective, centering on a finegrained analysis of the activities of key individuals embedded in project contexts $[7,8]$. On the basis of the actual activities or "praxis" of project managers, or the "practitioner" [9], we develop a framework of practices, the routines of behavior used to manage projects. Extending beyond projects alone, an understanding of such issues has been proposed to be informative for understanding the functioning of other weakly structured organizational settings as well, mostly those that are characterized by a high task interdependence and a limited time frame [10].

The present paper fits in a recent stream of work 
which views projects as temporary organizational forms [10], and builds more specifically on those studies which have acknowledged a practice gap in project research $[3,11,12]$. This focus on practices is different from the extant body of literature in what (project) managers actually do on a daily basis $[13,14]$, or studies on what skills, roles, tasks, competences or characteristics make project managers effective $[11,15,16]$. Furthermore, we focus on the practices project managers use to manage their projects on a daily basis, rather than the social practices they use in forming project networks [17].

As such, this research contributes to the understanding of project management in a number of ways. First, we include actual project practice in project theory. Although project managers are traditionally the subject of many handbooks, these are generally based on best practice (what project managers should be doing), rather than on actual project practice (the routines of managing projects). We believe that a thorough understanding of how project managers enact their project management is important as it, for one, likely helps to better engage with project managers "out there" (who are, incidentally, with over 400,000 members in the Project Management Institute alone certainly a sizable group of people). Knowing what people currently do (i.e. actual practice) is arguably important information for anyone who seeks to change this into something else (i.e. best practice).

Our second contribution lies in the micro-perspective we adopt. Lundin and Söderholm's [18] seminal work proposed action to be the guiding rationale underlying temporary project organizations vis-à-vis other types of organization. Although valuable, these insights did not yet elaborate how such action (i.e. human activity) would be constituted in practice. By taking the widely accepted view of practice as pertaining to situated human activities [19], rather than some of the other, more loose, applications which have positioned practices as including artifacts as well [20], we offer a micro-understanding of how action is constituted in projects. In other words, by an understanding grounded in what it is people do every day to get their work done [19], we offer an alternative to the existing project theories that are dominated by a systems perspective [11]. A third way in which our approach specifically contributes to existing work $[12,21]$ is that our analyses are sensitive to various project contingencies, taking seriously the notion that certain practices might be specific to certain project contexts [22]. Our focus on practices in understanding project management allows for an analytical comparison of routines across project dimensions. As such, our framework composed of sets of practices provides for a more coherent basis for comparison across projects compared to the frameworks of daily activities described by leadership researchers [13, 14].

\section{Theoretical Background}

\subsection{Project Management: The Management of Temporary Organizational Forms}

Research on projects and their management has a long standing tradition, mainly in engineering (see [23] for an overview). As a theoretical field, project management dates back to Henry Gantt, and the Gantt chart which closely related to Taylor's principles of scientific management. Now famous project planning techniques, such as CPM and PERT, were developed in the 1950s and have over the years developed both in number and in sophistication. These techniques, and the elaborate scientific tradition behind them, reflect the importance of goals, plans, schedules, and formulas in the dominant theoretical perspective adopted in project research [5]. As Söderlund [11: p. 372] has emphasized: "the project management literature generally focuses on [...] introducing work breakdown structures, Gantt-schedules, etc. [..]". As mentioned, numerous authors have pointed toward some of the (often implicit) assumptions this "traditional" paradigm works on, namely that 1 ) the role of the project manager is that of a planner and scheduler; 2) a project can be understood in relative isolation from its history and context; 3) every project is unique; and 4) a project is a tool, and as such highly moldable and transparent (and all of these have been demonstrated to be problematic in various degrees, [4,5,11]. As an illustration of this paradigm, Lewis [24: p. 4], for instance, defines a project as a one-time, multi-task job that has clearly defined starting and ending dates, a specific scope of work to be performed, a budget, and a specified level of performance to be achieved. From this vision of projects, the project manager is described as being one with total responsibility for ensuring that the project is completed on time, within budget, within scope, and at the desired performance level [24: p. 7].

Born from a dissatisfaction with this traditional project management paradigm, special issues by the Scandinavian Journal of Management in 1995 and Organization Studies in 2004 shook up the predominant conception of projects $[18,25]$. The major claim of this work and the considerable body of research which emerged since then is that projects should be re-positioned as temporary organizational forms $[6,26]$. This different perspective has implications in many areas, like the aforementioned primary concern with people rather than tasks and descriptive rather than prescriptive theory [5], but it has also opened the door to studying the behavior and social interactions that occur in projects [10], and learning [27] [28]. This constitutes quite a leap from what traditionally has been done in project studies, as it implies an emphasis on the more socially oriented processes that shape management $[24,29,30]$. Still, however, we know rela- 
tively little of the micro-processes going on in such temporary organizational forms, and its link with practice is unclear [11].

\subsection{A Practice Perspective on Project Management}

Therefore, we suggest relating the study of projects (viewed as temporary organizational forms) to "the practice turn" in social sciences [31]. In brief, this practice turn has attracted attention to what it is people actually do [32] rather than on scientific rationalism through detachment and abstraction [9], see Johnson et al. [33] for an excellent overview of theoretical underpinnings). This entails a focus on human activity, from the minute to the extraordinary, the situation of this activity in wider institutions; and a concern for human agents and the skills and resources which inform how they perform activities $[33,31]$. Practices, in this regard, revolve around the activities of people and the context in which such an activity occurs, and they are often defined as "the situated recurrent activities of human agents" [19: p. 253]. Practices closely resemble what Feldman and Pentland [34: p. 27] deem performative routines: "specific actions, by specific people in specific places and times".

Building on a practice perspective, the work by Feldman and Pentland [34,35] offers a novel perspective when it is applied to the management of projects. Feldman and Pentland draw attention to the fact that concepts consist of a structural, abstract side (the ostensive dimension) and of a performative dimension-the enactment of this concept in practice. We would propose that project management (a noun) in the traditional paradigm has mainly referred to the ostensive dimension, connoting elements, facts, and dispositions, whereas the performative dimension of project management (perhaps best thought of as managing projects, a verb connoting action, doing, and practice, [19] has been left relatively unexplored, even though the two recursively influence one another [36]. It is in line with this practice perspective that our empirical study of managing projects focuses on the routines that project managers undertake in their task of managing projects.

\section{Methods}

Because we strived for a detailed, in-depth analysis of the practices of project managers and the activity-based dynamics behind them, we opted for a qualitative methodological approach [37]. Between November 2005 and July 2006, 86 project managers were interviewed by a research team (including the authors) which was welltrained in qualitative methodology and interview techniques. All interviews lasted from 30 minutes to over 90 minutes in length, and were conducted one-on-one with the informants, often in their private offices. All but four interviews were fully tape-recorded and transcribed.

\subsection{Informants}

A total of 86 project managers participated in the research. An effort was made to interview informants from a variety of demographic categories. As a result, the informants interviewed ranged between ages 21 and 60, with a mean age of $43.25 \%$ of the project managers were under the age of 37 , and over a third was over 50 . Female project managers accounted for $10 \%$ of the project managers in our study, indicating the masculinity of the profession. Most of the participating project managers held Bachelor (39\%) or Master degrees (38\%), with smaller groups not having gained an advanced degree $(12 \%)$, or conversely having obtained a post-graduate degree (11\%). On average, the informants worked a little over 40 hours a week. Almost a third of the interviewed project managers worked 38 hours per week or less, and another third worked over 50 hours.

All informants belonged to different project ventures, and were appointed and active as a project manager at the time of the interview. We did identify, however, considerable variation in the kinds of projects that the project managers were responsible for. In line with previous literature $[22,38]$, we distinguished along multiple dimensions of variation between projects. The duration of the project was equally distributed over three classes: $\leq 6$ months $(\mathrm{N}=23), 7-15$ months $(\mathrm{N}=22)$, and $\geq 15$ months $(\mathrm{N}=20), 21$ projects had an undefined duration. The second dimension referred to the uniqueness of the project tasks: unique $(\mathrm{N}=59)$ or routine $(\mathrm{N}=17)$, for 10 projects the uniqueness was undefined. Finally, we distinguished between the organizational status of the project: intra-organizational $(\mathrm{N}=35)$ or inter-organizational $(\mathrm{N}=47)$ while 4 projects combined an intra- and interorganizational focus.

\subsection{Data Collection}

Our data collection focused on the work practices of project managers and was exploratory in nature. Our unit of analysis in this endeavour was the activity itself. In order to circumvent the recently expressed problems with uncovering practices in management when asked directly [39] we took the following approach. In order to probe deeper into how the general management tasks were enacted into everyday practice, participants were subsequently asked to narrate about their everyday activities by recalling a certain concrete episode, typical of their on-going project work. This approach essentially resembles the Critical Incidence Technique [40] which promotes having informants talk about concrete action by having them think of a particular series of events. The 
above was codified in an interview guide for the whole research team, which was not rigidly constrained to allow unexpected topics to be pursued as well. We should stress that by this approach we thus let informants come up with important activities themselves, rather than that we prompted them with a pre-defined range of practices to choose from $[20,41]$.

We took several steps to enhance reliability. First, a large amount of interviews (86) was conducted, and all interviewers had received training in interview techniques. The use of multiple interviewers decreased the odds of systematic interviewer effects. Secondly, a common interview protocol was used for all interviews, ensuring that comparable information was collected during all sessions. The research team wrote background reports on the context of the project ventures they studied (participants, strategy, size, sector, etc.), which allowed to check the quality of the data collected. Thirdly, we checked the information gathered through the primary source of data collection, in-depth interviews, with information collected through other sources, including any background project documents that could be obtained (e.g. a project plan, minutes, etc.).

\subsection{Analytic Approach}

Since little is known about the actual day-to-day activities of project managers, our orientation toward data analysis was exploratory, with the earlier stages being more open than the later stages. The method of analysis we employed draws mainly on the work by Strauss and Corbin [42] and Miles and Huberman [43]. This approach entails continuous comparison of data and concepts throughout the analysis phase. Since in this study data analysis followed data collection, we travelled back and forth between data and emerging concepts, and, later in the process, between the concepts and evidence [44].

We commenced the content analysis by developing a crude framework on the characteristics of managing projects based on brainstorm sessions and a first reading of the interviews. This initial framework yielded a tentative list of sensitising concepts that were used to guide the analyses. In subsequent rounds of coding and analysis we allowed additional constructs to emerge from the data, rather than to be guided and constrained by specific hypotheses. Using Atlas-ti, we further developed and refined the concepts by a constant contrasting and comparing to the data, thus building a framework that described the activities and practices of managing projects. In line with our theoretical framework, the unit of analysis herein was the leader's activity (praxis), of which we identified and coded 57 unique and meaningful ones that were mentioned in more than one interview (see Appendix). Following leading research in this terrain [19], we then aggregated and clustered these emerging activities into repertoires of practices routinely performed by project manages, and subsequently linked these to particular kinds of projects. We concluded the analysis of the interview data with a line by line reading of all transcripts for validation of our findings.

In the above analyses we achieved inter-coder reliability through switching the data between the researchers, coding transcripts independently from each other, then discussing labels and codes and then recoding the data. During this procedure, a clear stepwise procedure of coding, recoding and categorising the data was established.

The final step in our analyses concerned an examination of how the emerging practices we found might relate to specific project contingencies. We exported all practices from Atlas-ti to an SPSS database, which included for each interview whether a certain practice was present or absent, as well as the type of project it concerned. As mentioned, we distinguished in this regard between projects of short, middle and long duration, unique and repeated projects, and inter-organizational and intra-organizational projects. By inspecting associations between the practices and project-contingencies, we analyzed whether the practices of project managers we found were universal, or rather specific to specific type of projects.

\section{Results: Everyday Practices}

Through our data analysis we identified 10 repertoires of practices that project managers engage with in their dayto-day work. Each of these 10 practices consists of bundles of associated minute activities. We grouped the practices by different domains, in order to structure the discussion analytically: managing process, managing people, managing the environment, and managing information. Before we briefly elaborate each of the practices in these domains, it should be noted that they should not be seen as exhaustive or exclusive.

\subsection{Managing Process}

The first domain of practices that we identified pertains to what we deem managing process. This domain is built up from four practices, which we deem setting the pace, taking action, forecasting and budgeting. We will elaborate each of these below.

\subsubsection{Setting the Pace}

One of the central features of projects concerns the fact that they are temporary [18]. As such, time and temporality are highly salient aspects in project management. What we deem setting the pace (mentioned by $\mathrm{N}=55$ project managers), has to do with keeping time, setting milestones and deadlines, pacing, and ensuring entrainment with external organizational processes (see Appen- 
dix).

Finishing in time is crucial for the success of a project [6]. Setting the pace, and managing the temporal process more generally, is therefore one of the central practices in managing projects. As one informant indicates:

"In a temporary project organization you work with tight deadlines. You are a planning project manager. You write a project plan, set milestones. The deadlines that you need to make. You keep track of the planning and take care of what people should do. You have the helicopter vision. You make sure people make everything in time. [..] You are working more on the time planning than on coaching and directing the people themselves" [R84: p. 33] ${ }^{1}$.

Essentially, setting the pace thus refers to a range of activities that have in common the fact that project managers need to map and amend the temporal process of the project. A crucial aspect hereof concerns the setting of milestones and deadlines. One informant mentions:

"The time pressure implies a constant process of making the people aware that things need to be finished, so [I need to] set dates, and closely monitor that if things aren't ready yet, they will be taken care of soon" [R16: $\mathrm{p}$. 42]

In other words, the practice of setting the pace is about making people stick to process, about "[..] trying to generate enthusiasm, but when there is a diversion from the plan in terms of [..] time, that you call someone to account" [R30: p. 14], so that ultimately, the project deadline can be met.

\subsubsection{Taking Action}

What we label the practice of taking action is associated with activities such as making decisions, taking charge of the situation at hand, sanctioning, giving account, and prioritising certain processes over others (see Appendix). It was mentioned by 60 project managers.

Taking action is according to the project managers in our sample one of the core practices within project management. In many situations, project managers are faced with difficult decisions under a relentless time pressure. The following citation illustrates this:

"Some operational issues needed to be dealt with first. The time pressure was enormous, because the repository needed to be emptied and customers had to get their orders as quickly as possible. These urgent situations demand you to be very harsh. These are times that decisions need to be made and that it's better to make a bad decision then no decision at all. Everything has to swing into action, blaming comes later. All members needed to be pushed into the right direction, members who did not

\footnotetext{
${ }^{1}$ The digits between brackets refer to our interview transcripts to be able to locate them easily. E.g. [R62:50] refers to the interview with Respondent 62 , line 50 .
}

see the gravity of the situation had to be convinced. In the beginning this asks for a dominant performance and frequent motivation of the members. Of course I was open to suggestions, but with the aim to solve the problem" [R62: p. 50].

But next to taking charge of decisions and problem solving, taking action also means that project managers work overtime to write proposals, and actively prioritize certain tasks over others. According to another informant, project managers have to "keep going and distinguish priorities very quickly" [R32: p. 63]. This includes focusing on some issues and disregarding others, because the short time horizon obligates project managers to take action. In other words, since they operate in often complex environments and with strict deadlines, project managers seem to take action in order to make decisions, induce action, and prioritize when necessary.

\subsubsection{Forecasting}

The practice that we label forecasting concerns the planning and scheduling activities that project managers engage in on a day to day basis ( $\mathrm{N}=42$, see Appendix). The difference between forecasting and setting the pace mentioned above, is that forecasting has mainly to do with the future direction of where the project is headed, whereas setting the pace is concerned with the speed at which it gets there.

The importance of forecasting as pertaining to the activities by which plans and schedules become realized, is captured by one of the informants in our study as follows:

"In order to achieve that [the project goal] we draw up a project planning and on the basis of that plan, [...] the project is executed. So the guideline for the whole execution is project planning" [R30: p. 8]

According to our informants, forecasting is not only crucial for the success of the project; it should also be done in advance, before the execution phase of the project. One informant has a less than perfect experience in this regard:

"Off course I know that you can't foresee everything and that some problems are always bound to happen, but by a thorough preparation you can try to minimize such problems. It goes too far to assign blame to anybody in particular, but more research should have been done in the preparation phase" [R62: p. 70]

Forecasting thus is a vital element in managing projects, especially in the start-up phase of the project, in which it is crucial for the success of the project that the project manager has a clear understanding and vision of the project's timeline and where it is heading.

\subsubsection{Budgeting}

The final important activity which we distinguished in 
this domain concerns budgeting. This practice pertains to the budget that is awarded to the project and the guarding hereof, and is mentioned in 23 interviews. The following quotation illustrates the centrality of budgeting to managing projects:

"The most important point [in project management], and I always emphasise this, are finances" [R72: p. 50].

The importance of budgeting for managing projects relates to the nature of projects as temporary, resourceconstrained entities [6]. Having to make do with a bounded budget makes the activity of guarding finances crucial:

"So you say: "I've got $900 \mathrm{~K}$ to 1 million available" and then you see whether you can realize it [the project] within that budget" [R19: p. 10].

Within the boundaries of the budget, however, managing projects is about the careful allocation of resources, and the project manager generally has discretion in this process:

"And you have that freedom. Off course, a $100 \mathrm{~K}$ is a $100 \mathrm{~K}$, but within that $100 \mathrm{~K}$ you have room for manoeuvring between different options" [R67: p. 86].

Completing the list of activities which seem to predominantly constitute managing process in practice, budgeting is an important activity in which project managers engage.

\subsection{Managing People}

The second domain of practices we identified in the narratives of project managers concerns what we deem managing people. This domain is constituted in three practices: communicating face-to-face, giving responsibility, and team building,

\subsubsection{Communicating Face-to-Face}

The third most prevalent practice we encountered in our analyses of the narratives of our informants concerns what we deem communicating face-to-face $(\mathrm{N}=50)$. Communicating face-to-face comprises minute activities such as communicating transparently, meeting and consulting with project workers, and listening (Appendix). The following quotation from one informant illustrates the important place of communicating within the realm managing projects:

"Communication is very important, you need to make a communication plan to inform the people directly related to the project but also surrounding the project of what is happening and what will happen" [R16: p. 42].

Project managers communicate during meetings and moments of informal communication about their plans, decisions, and progress. Furthermore, they discuss personal problems, gear tasks to one another, and communicate agreements with project members. As one informant explains, this needs to be done face-to-face:
"You have to do this [communicating] in a very personal way, in other words you need to take the time to explain every worker, every manager, what needs to be done and give them time to react" [R63: p. 128].

Communication is often aimed to create an atmosphere of transparency, which helps to gain support. One informant illustrates this by the following anecdote:

"Many parties in the project were irritated by the attitude of the Norwegian representative [...] and this clearly limited the progress on the project. I then went to Norway and took him to a small bar in Trondheim. At a certain moment, I reached the situation in which I could ask him what he thought the group thought of him. I noticed that he was now open to feedback, and that he noticed himself that his behavior was unproductive [..] In that small bar I connected with him, as it were [..]" [R57: p. 85].

The above excerpt nicely illustrates how communicating face-to-face has added value over other forms of communication, and how it entails more than just sending information; it also forms much of the glue that keeps the project venture together. Moreover, it should be noted that communicating face-to-face is a two-way process: it involves listening as well as sending information.

\subsubsection{Giving Responsibility}

The practice that we deem giving responsibility was mentioned by 44 of the project managers in our sample. Giving responsibility comprises activities such as delegating, asking project workers for help, and asking for input (see Appendix).

The following quotation by one of the informants illustrates this practice:

"I can't decide anything without them [the project team members]. They have the specific knowledge. I know a lot about the organization and I have many contacts, but when I have to advise the board [..] I need input from my project team to compose an email or to 'escalate' as we call it. We recently had problems in the training module. It was a technical problem of which Peter, one of the trainers, knows a lot. I needed to escalate this problem, but I needed him in order to handle this properly" [R61: p. 38].

In other words, an important element in giving responsibility concerns the fact that project managers are not necessarily content experts on the projects they manage [24]. Giving responsibility is also a practice which project managers consciously perform as a tactic to increase involvement. As one informant mentions:

"When you attribute responsibility low in the project organization, people will feel involved in it" [R29: p. 188].

\subsubsection{Team Building}

Team building is mentioned by 49 of the project manag- 
ers as being an important practice in managing projects. Team building involves activities such as motivating, creating support, the management of uncertainty and stress, coaching of workers and the management of conflict (see Appendix). As such, it stresses the "human" or "social" side of managing projects [29]. As one informant indicates:

"Every four weeks or so [...] I try to meet with the project team in the cafeteria to have a beer together. At Christmas or Easter or so, I also try to do something different for the project team, be it just passing around chocolate. Such small things are always highly appreciated. The fact that people feel 'we are a team', 'we do this for one another', 'we help one another'... that's what I always try to inspire" [R52: p. 112].

The above excerpt nicely illustrates the importance project managers attribute to the "soft side" of managing projects. In general, there is a broad consensus among the informants we interviewed that team building is an important activity in the managing of projects and that it pays off, in the sense that it leads to a good atmosphere, commitment and motivated project workers.

\subsection{Managing the Environment}

The third domain we identified in the narratives of project managers, managing the environment of the project, is built up from two practices performed by project managers, which we deem representing and politicking.

\subsubsection{Representing}

One repertoire of activities we identified in the narratives of the project managers we interviewed concerns what we label representing $(\mathrm{N}=47)$. Representing is about representing the project and its progress toward external stakeholders such as line managers in the external organization and the board. It includes activities such as communicating externally, creating external support for the project, and involving external parties in the project (Appendix). The rationale for representing the project to external parties lies in creating legitimacy and support for the project. In the words of one of the informants in our sample, this is important because of the role of the external line organizations in decisions pertaining to the project:

"When decisions are being taken, the project manager generally does not have a hierarchical line within the organizations that take part in the project. That is one of the first things you need to deal with. Besides the daily manpower that you need to shape the project, there needs to be in place a consultative structure with people who do have a hierarchical line within the organization. Generally, these are administrators of the organizations concerned" [R72: p. 23].
This dependency on a great many outside parties makes it important for project managers to realize how their project relates to other projects and processes that extend beyond the project itself. From these circumstances arises the importance of representing the project to external stakeholders. In representing, it seems important to use politicking strategies (practice six discussed below) when engaging the environment.

It seems, then, from our data that one aspect of managing projects concerns representing the project to its environment, in order to claim a work force, and gain support and legitimacy among external stakeholders. This emphasizes yet again the importance of external context for issues taking place within project ventures [4].

\subsubsection{Politicking}

Politicking, the display of political behavior, was mentioned by 44 project managers in our study. It consists of activities such as lobbying for support, networking, negotiating, manipulating, and influencing actors in the project's environment (see Appendix). The importance of politicking in managing projects is well captured in the words of the following informant:

"This is a very important quality of project management...because you work with so many partners, you in this line of work need to constantly think about 'what does the other think?', 'what are the other's interests?" because they all have their own agendas with respect to developments. This is important, that you during a conversation are able to think in terms of 'he's saying this, but what he actually means is that, and this is what he wants to get out of it'. So you always need to think carefully before bringing people together. What are the interests and what do you want to get out of it? Actually, you need to manipulate people without saying that you are manipulating, and without showing that you do" [R37: p. 61].

The above is a clear illustration of the political processes that project managers constantly engage in. For project managers this is likely compounded by them dealing with so many interdependent actors simultaneously [29]. An interesting predicament, then, concerns how project managers can deal with these many, and often conflicting interests, while under time pressure and keeping the pace (mentioned above). One informant has an interesting take on this:

"Still I thought it would be impossible to include 500 people, so what we did was we picked out the biggest critics and involved only those. And with that I mean not the [profanity] because you have those everywhere, but the people who have been working here for some years and who are in good standing with their colleagues, but who often comment critically on things. Those people we 
showed the new design" [R50: p. 47].

Essentially, this approach is reminiscent of Eisenhardt's [45] work on how managers make fast decisions in high velocity environments by involving a relatively small group of key informants in decision making. This practice thus seems germane to managing projects as well. As such, the practice of politicking thus seems to enable project managers to manage contradictory tensions in short time periods, and get a grip on processes and decisions which are formally out of their control. The central position of politicking within the managing of projects was shared broadly among our informants.

\subsection{Managing Information}

The fourth and final domain of practices we identified concerns the managing of information, which is constituted in one practice, namely integrating knowledge and information.

\section{Integrating Knowledge and Information}

An important activity which we distinguished in the narratives of the project managers we interviewed concerns integrating knowledge and information. This practice was mentioned by 35 informants, and pertains to activities such as bringing together information, codifying, and doing (preliminary) research (see Appendix). The central place of such activities in project management is well captured in the words of the following informant:

"My way [of managing projects] is by bringing together information. So that everybody has their say, that the weaker parties in the process have their own roles, [..] protecting everybody's perspective from being ridiculed.. so the bringing together of all kinds of information in good harmony" [R73: p. 98].

Presumably, integrating information and knowledge is a particularly important aspect of managing projects because capturing knowledge is generally regarded as a major challenge in projects [46] and projects generally comprise many diverse skills and knowledge bases [47]. The following quotation is illustrative of the latter:

"What makes it hard is that every solution must be integrated, in other words, that it must be looked at from every important perspective. Every perspective has certain pros and cons and certain consequences. It takes skill to judge which of these pros and cons and consequences are most important in order to in the end make a certain choice" [R53: p. 12].

A central place within the management of projects is thus awarded to the integration of knowledge and information of the diverse knowledge bases involved in the project, and the careful weighing of different bits of information by its relevance for the project.

In sum, the above set of four domains, and the 10 prac- tices which constitute them in practice, forms the performative dimension of project management, how it is enacted by human agents. As mentioned, this set is neither exhaustive nor mutually exclusive. In our view, however, they together do begin to offer an interesting insight in how action is shaped in projects. We will in the following elaborate on this point, and discuss what these practices together imply for our broader understanding of project-based organization.

\section{Discussion}

Our results have a number of direct theoretical implications. We will elaborate these implications below, and position them as theoretical building blocks for a practice-perspective of project-based organization, as an alternative to those theoretical assumptions underlying what we deemed the traditional project management paradigm above.

\subsection{Building Block 1: Managing Projects Is about Planning and Control-But Only Partly So}

A finding which flows rather directly from the practices we found pertains to the supposed predominance of planning and control within project-based organization. As mentioned, the traditional paradigm has thus far set forth that planning and control are the core tasks of project managers [5]. Our findings on the prevalence of project practices offer a more fine-grained perspective.

Specifically, our results indicate that practices which we would associate with "hard" planning and control (i.e. managing process: setting the pace, taking action, forecasting, budgeting) together only account for 4 out of the 10 practices that were mentioned by our informants. This holds when one takes into account their relative weight (in terms of the amount of times that one of these practices was mentioned in the narratives, as a proportion of the total amount of times all practices were mentioned: $181 / 450=40.2 \%)$. This implies that besides planning, other practices are important as well. Three of these that stand out in our findings concern the management of people (associated with the practices communicating face-to-face, giving responsibility, team building), the management of knowledge and information (associated with the practice by the same label) and the management of the project environment (associated with the practice of representing and politicking). These seem well in line with the view of projects as temporary organizational forms that has been forwarded recently [10], of which it is a given that they involve people, that knowledge is crucial for their competitive advantage, and that they are embedded in an external environment [4]. Moreover, our results indicate that all these practices are highly inter- 
connected: in fact, planning and control seem to be reciprocally reinforced by the other practices such as team building and politicking, of which it cannot be separated. Seeing projects as practice thus goes one step further in acknowledging the project as temporary organizational arena, by demonstrating that project managers besides planning and controlling work not only also have an obligation toward project participants (people), but to knowledge management, and the environment as well.

Therefore, a first building block for a practice perspective of project-based organization concerns that the core of managing projects is not just limited to a management of process, but includes activities pertaining to people, knowledge and the environment as well.

\subsection{Building Block 2: Project Practices Are Situated in Specific Types of Projects}

As was mentioned, the traditional paradigm in project management has proposed all projects to be unique, implying little variation between different kinds [38]. In contrast, we distinguished between the different kinds of projects our informants managed along multiple dimensions, and studied the extent to which there were associations between these project contingencies (duration, uniqueness of tasks, and organizational status) and the kind of practices being mentioned. We found that of these three project contingencies, duration yielded the most significant differences. We thus focus our discussion on this project contingency.

Figure 1 presents the amount of times the practices setting the pace, budgeting, communicating face-to-face, and giving responsibility were mentioned by project managers in respectively short ( $\leq 6$ months), middle ( 7 15 months), and long duration projects ( $\geq 15$ months). The other practices did not significantly co-vary with project duration or the other project contingencies. Our tentative conclusion toward these practices (taking action, team building, representing, politicking, forecasting, and integrating knowledge and information) is that they are reasonably universal over unique and repetitive projects, intra- and inter-organizational projects, and projects of different duration.

With regard to setting the pace, communicating faceto-face and giving responsibility, Figure 1 indicates that they show a similar pattern: they are most prevalent in projects of intermediate duration, and least prevalent in projects of short duration. We assume that this is the case since in projects of very short duration there is not the time, the room, or the inclination, to engage in high frequency managerial activity, as presumably everything is geared toward completing the project task [48]. Although we would have expected, based on this reasoning, to find setting the pace to be relatively more prevalent in short duration projects, one possible explanation it is not,

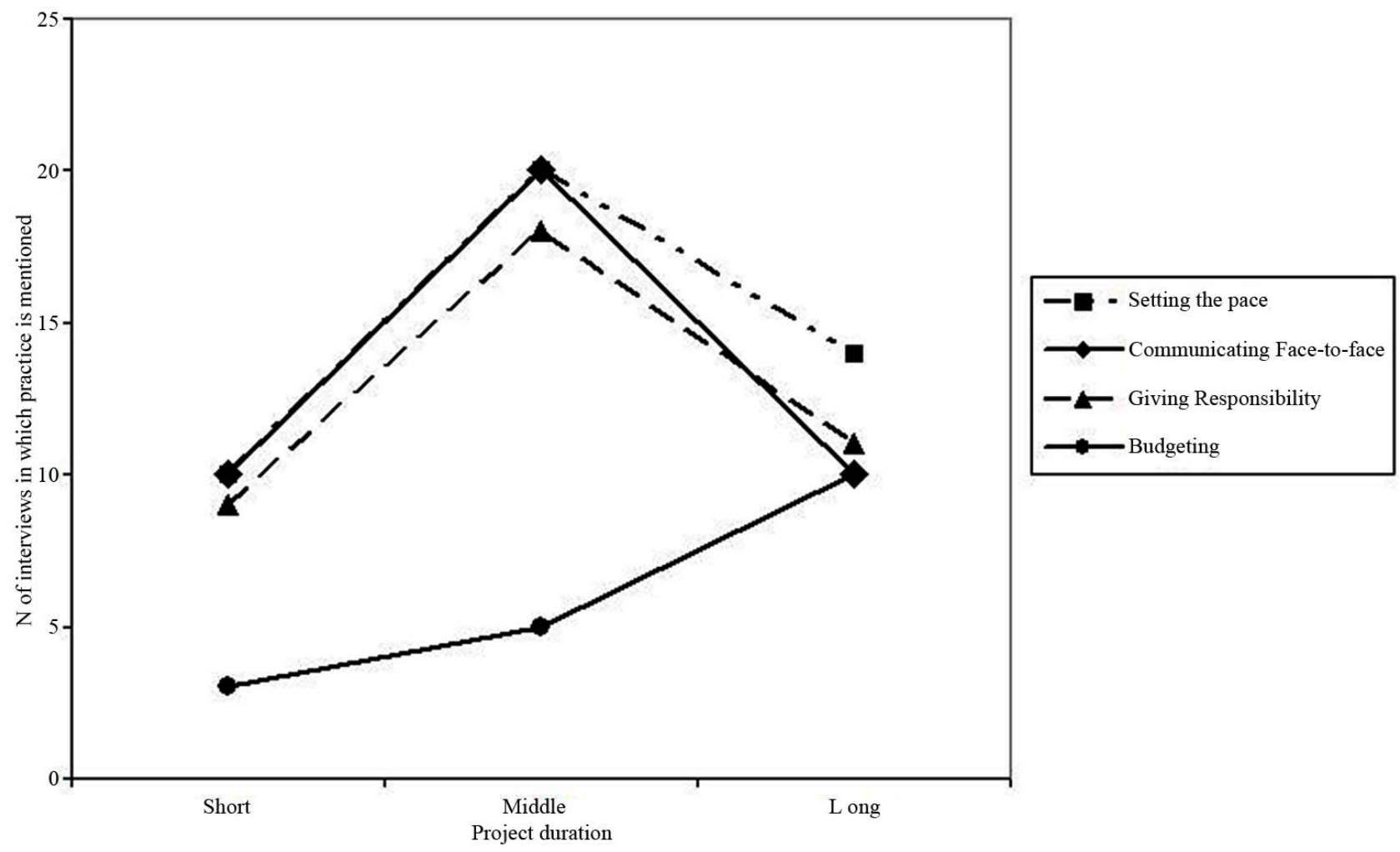

Figure 1. Differences in practice prevalence by project duration. 
might be that in projects of such short duration, the deadline is obvious and visible to everybody, and needs therefore little planning, or extra managerial activity [18]. An alternative explanation might be that this planning activity in short duration projects is done beforehand by the parent organization, and is therefore no task of the project manager. In long duration projects, the other extreme, the pressure to engage in excessive managerial activity might be relatively lower than in short and intermediate duration projects. Taking setting the pace again as case in point, it might well be that because in long duration projects there is a longer and more complex time planning involved (which might be subject to change during the project as well), we see relatively more setting the pace activity here than in short duration projects. However, some of the room to engage in this activity in longer duration projects might be offset by the lower time pressure these projects are under, which would dampen the need to engage in a high intensity of project practices. In projects of intermediate duration, these two then come together, because there is on the one hand both the room and inclination to engage in communicating, giving responsibility and setting the pace behavior (as in long duration projects), and on the other hand there is also time pressure which forces project managers to engage in high frequency activity to reach project goals (as in short duration projects). An exception to this pattern concerns budgeting, the prevalence of which increases monotonically with longer project duration. We assume that this might be due to the fact that many of our informants indicated that in contrast to the other practices, budgeting is an activity they mainly engaged in at the beginning of the project, and therefore not under influence of project dynamics taking place after this time. It makes sense, however, that this early-phase budgeting is more complicated for longer, more elaborate projects, which would explain our finding.

In any case, in contrast to the traditional project management paradigm, our findings imply that certain practices co-vary with project contingencies. Therefore, the more general implication of the above analyses would be that project practices can be specifically situated in particular types of projects.

\subsection{Building Block 3: Managing Projects Is an Activity Aimed at a Continuous Recoupling of Diverse Practices}

We found that the practices we identified on the one hand show a high degree of diversity, yet there are also places where they overlap. Politicking and representing, for instance, seem to closely relate to one another under managing the environment, as often project managers appear to represent (i.e. engage the environment) by politicking (influencing relevant stakeholders). The means by which this happens concerns yet another closely related practice, namely communicating face-to-face (managing people). In other respects, however, there seem tensions between practices: between taking action and giving responsibility, for instance, which project managers need to closely balance; giving responsibility in order to increase involvement, while taking action in order to move things along. In addition, project managers on the one hand engage in team building activities in order to create support and build a cohesive team, yet on the other hand need to strictly set the pace, to make sure deadlines are met.

The overall picture that emerges is one of project managers struggling to deal with the complex tasks, high interdependence and time pressure that together constitute the "messiness" of project life [47]. This clearly contrasts the traditional project management paradigm, which, as mentioned, proposes projects to be highly mouldable and transparent [11]. Our results rather indicate that by engaging in many different practices, often not sequentially but simultaneously, project managers try to come to terms with the complexity and social ambiguity of project work. It seems then, that managing projects is to a large extent about keeping some degree of overall coherence and integration over sometimes diverse and contradictory, yet at other times partly overlapping activities, which are at constant risk of disengagement and fragmentation [49]. Our results thus imply that from a practice perspective, project organization as it is enacted by project managers might correctly be seen as an activity, one geared toward a constant coupling and recoupling of diverse practices over time, into a coherent role which others view as that of project manager.

\subsection{Building Block 4: Projects Act as Temporary Points of Intersection for Social Practice}

Our results finally indicate that a practice theory of project-based organization should be sensitive to the role of the project as context in which practices take shape. We mentioned how the traditional project management paradigm has thought of a project as a "phenomenon isolated from its history, stripped of its contemporary social and spatial context and independent of the future" [46: p. 1492]. The practice perspective we adopted offers an alternative view of projects as context, by acting as a temporary point of intersection for a wide range of social practices [49]. We just demonstrated that some practices are situated in specific kinds of projects. This implies how temporary organizational work settings constitute the social arenas in which project activities gain their meaning. As such, a project, as a contextual practice arena, recursively shapes and is shaped by project practice [12] and is therefore vital to the functioning and understanding of project practices. Our final alternative assumption, then, 
holds that practices can only be understood in the project context, which acts as a temporary point of intersection for social practice.

\subsection{Limitations}

Despite our efforts, there are a number of limitations to our study. First, as a preliminary and exploratory endeavour in this terrain, our findings should be regarded as tentative only, and the practices mentioned in the present article are not "all" project managers do. Undoubtedly, they do more. We did not literally ask project managers what they did; we merely let them spontaneously narrate about a critical event in a recent project, and systematically analyzed the activities they mentioned. By this approach we hope to have gained a more in-depth perspective on what it is project managers actually do, compared to the aforementioned other methodological approaches in which respondents are presented with a pre-defined list of activities to choose from [20]. Our methodological approach also has a downside, however, in that certain practices which are "too obvious to mention" might, in fact, not be mentioned in the informant's narratives. In the end, what our informants told was what they perceived to be their actions in a certain project episode. A third limitation concerns that although we controlled for some project contingencies, we could not include all. After this study, our hunch would be that the prevalence of the practices we found might also differ in different project phases. This is an avenue that future research might consider.

\section{Conclusions}

The present paper aimed to offer a practice perspective on project-based organization, alternative to the traditional project paradigm rooted in engineering that has dominated this field thus far. As was mentioned, this traditional paradigm has been shown to hinge on a number of implicit theoretical assumptions, namely: 1) the role of the project manager is that of a planner and scheduler; 2) a project can be understood in relative isolation from its history and context; 3 ) every project is unique; and 4) a project is a tool, and as such highly moldable and transparent. As was mentioned, all of these have been proposed to be problematic in one or more respects $[4,5,11]$.

Our detailed study of 86 project managers yielded 57 activities that shape 10 repertoires of practices they perform. These practices show little overlap with those grounded in the traditional theoretical paradigm [41]. Rather, our findings forward an empirically grounded set of alternative assumptions, namely that managing projects 1) is only partly about planning and scheduling, and comprises many other activities in multiple domains as well; 2) is locally situated in specific types of projects; 3 ) is an activity aimed at a continuous recoupling of diverse practices; and 4) is shaped by project contexts, which act as temporary points of intersection for social practice.

\section{REFERENCES}

[1] R. M. Bakker, J. Knoben, N. De Vries and L. A. G. Oerlemans, "The Nature and Prevalence of Inter-Organizational Project Ventures. Evidence from a Large Scale Field Study in the Netherlands 2006-2009," International Journal of Project Management, Vol. 29, No. 6, 2011, pp. 781-794. doi:10.1016/j.ijproman.2010.04.006

[2] M. W. Lewis, M. A. Welsh and G. E. Dehler, "Product Development Tensions: Exploring Contrasting Styles of Project Management," Academy of Management Journal, Vol. 45, No. 3, 2002, pp. 546-564. doi:10.2307/3069380

[3] D. Dougherty, "Organizing for Innovation," In: S. R. Clegg, C. Hardy and W. R. Nord, Eds, Handbook of Organization Studies, Sage, Thousand Oaks, 1996, pp. 424439.

[4] M. Engwall, "No Project Is an Island: Linking Projects to History and Context," Research Policy, Vol. 32, No. 5, 2003, pp. 789-808. doi:10.1016/S0048-7333(02)00088-4

[5] J. Packendorff, "Inquiring into the Temporary Organization: New Directions for Project Management Research," Scandinavian Journal of Management, Vol. 11, No. 4, 1995, pp. 319-333. doi:10.1016/0956-5221(95)00018-Q

[6] G. Grabher, "Cool Projects, Boring Institutions: Temporary Collaboration in Social Context," Regional Studies, Vol. 36, No. 3, 2002, pp. 205-214. doi: $10.1080 / 00343400220122025$

[7] P. Jarzabkowski, "Strategy as Practice: Recursiveness, Adaptation, and Practices-in-Use," Organization Studies, Vol. 25, No. 4, 2004, pp. 529-560.

[8] G. Johnson, L. Melin and R. Whittington, "Micro Strategy and Strategizing: Towards an Activity-Based ViewGuest Editors' Introduction," Journal of Management Studies, Vol. 40, No. 1, 2003, pp. 3-22. doi:10.1111/1467-6486.t01-2-00002

[9] R. Whittington, "Completing the practice turn in strategy research," Organization Studies, Vol. 27, No. 5, 2006, pp. 613-634. doi:10.1177/0170840606064101

[10] B. A. Bechky, "Gaffers, Gofers, and Grips: Role-Based Coordination in Temporary Organizations," Organization Science, Vol. 17, No. 1, 2006, pp. 3-21. doi:10.1287/orsc. 1050.0149

[11] J. Söderlund, "What Project Management Really Is about: Alternative Perspectives on the Role and Practice of Project Management," International Journal of Technology Management, Vol. 32, No. 3-4, 2005, pp. 371-387. doi:10.1504/IJTM.2005.007340

[12] A. Windeler and J. Sydow, "Project Networks and Changing Industry Practices: Collaborative Content Production in the German Television Industry," Organization Studies, Vol. 22, No. 6, 2001, pp. 1035-1060.

[13] H. Mintzberg, "The Nature of Managerial Work," Harper 
\& Row, New York, 1973.

[14] S. Tengblad, "Is There a 'New Managerial Work'? A Comparison with Henry Mintzberg's Classic Study 30 Years Later," Journal of Management Studies, Vol. 43, No. 7, 2006, pp. 1437-1461. doi:10.1111/j.1467-6486.2006.00651.x

[15] N. Pettersen, "What Do We Know about the Effective Manager?" International Journal of Project Management, Vol. 9, No. 2, 1991, pp. 99-104. doi:10.1016/0263-7863(91)90068-7

[16] P. B. De Laat, "Matrix Management of Projects and Power Struggles: A Case Study of an R\&D Laboratory," Human Relations, Vol. 47, No. 9, 1994, pp. 1089-1129. doi: $10.1177 / 001872679404700904$

[17] S. Manning, "The Strategic Formation of Project Networks: A Relational Practice Perspective," Human Relations, Vol. 63, No. 4, 2010, pp. 551-573. doi:10.1177/0018726709340954

[18] R. A. Lundin and A. Soderholm, "A Theory of the Temporary Organization," Scandinavian Journal of Management, Vol. 11, No. 4, 1995, pp. 437-455. doi:10.1016/0956-5221(95)00036-U

[19] W. J. Orlikowski, "Knowing in Practice: Enacting a Collective Capability in Distributed Organizing," Organization Science, Vol. 13, No. 3, 2002, pp. 249-273.

[20] C. Besner and B. Hobbs, "The Project Management Tools and Techniques: The Portrait of Current Professional Practice," Project Management Journal, Vol. 37, No. 3, 2006, pp. 37-48.

[21] M. Hällgren and T. L. Wilson, "The Nature and Management of Crises in Construction Projects: Projects-asPractice Observations," International Journal of Project Management, Vol. 26, No. 8, 2008, pp. 830-838. doi:10.1016/j.ijproman.2007.10.005

[22] A. J. Shenhar, "One Size Does Not Fit All Projects: Exploring Classical Contingency Domains," Management Science, Vol. 47, No. 3, 2001, pp. 394-414. doi:10.1287/mnsc.47.3.394.9772

[23] P. W. G. Morris, "The Management of Projects," Thomas Telford, London, 1994. doi:10.1680/mop.16934

[24] J. P. Lewis, “The Project Manager's Desk Reference: A Comprehensive Guide to Project Planning, Scheduling, Evaluation, and Systems," McGraw-Hill, Boston, 2000.

[25] J. Sydow, L. Lindkvist and R. DeFillippi, "Project-Based Organizations, Embeddedness and Repositories of Knowledge: Editorial," Organization Studies, Vol. 25, No. 8, 2004, pp. 1475-1489. doi:10.1177/0170840604048162

[26] P. Kenis, M. Janowicz-Panjaitan and B. Cambré, "Temporary Organizations: Prevalence, Logic, and Effectiveness," Edward Elgar, Gloucestershire, 2009.

[27] T. Brady and A. Davies, "Building Project Capabilities: From Exploratory to Exploitative Learning," Organization Studies, Vol. 25, No. 9, 2004, pp. 1601-1621. doi:10.1177/0170840604048002

[28] H. Scarbrough, J. Swan, S. Laurent, M. Bresnen, L. Edelman and S. Newell, "Project-Based Learning and the Role of Learning Boundaries," Organization Studies, Vol. 25, No. 9, 2004, pp. 1579-1600.

\section{doi:10.1177/0170840604048001}

[29] A. T. Cobb, "Leading Project Teams," Sage, Thousand Oaks, 2006.

[30] L. Lindkvist, J. Soderlund and F. Tell, "Managing Product Development Projects: On the Significance of Fountains and Deadlines," Organization Studies, Vol. 19, No. 6, 1998, pp. 931-951. doi:10.1177/017084069801900602

[31] T. Schatzki, "Introduction: Practice Theory," In: T. Schatzki, K. Knorr-Cetina and E. Von Savigny, Eds, The Practice Turn in Contemporary Theory, Routledge, London, 2001, pp. 1-14.

[32] A. Reckwitz, "Toward a Theory of Social Practices: A Development in cultural Theorizing," European Journal of Social Theory, Vol. 5, No. 2, 2002, pp. 243-263. doi: $10.1177 / 13684310222225432$

[33] G. Johnson, A. Langley, L. Melin and R. Whittington, "Strategy as Practice: Research Directions and Resources," Cambridge University Press, Cambridge, 2007.

[34] M. S. Feldman and B. T. Pentland, "Reconceptualizing Organizational Routines as a Source of Flexibility and Change," Administrative Science Quarterly, Vol. 48, No. 1, 2003, pp. 94-118. doi:10.2307/3556620

[35] M. S. Feldman, "Organizational Routines as a Source of Continuous Change," Organization Science, Vol. 11, No. 6, 2000, pp. 611-629. doi:10.1287/orsc.11.6.611.12529

[36] A. Giddens, "The Constitution of Society," Polity Press, Oxford, 1984.

[37] F. H. M. Blackler and C. A. Brown, "Qualitative Research and Paradigms of Practice," Journal of Management Studies, Vol. 20, No. 3, 1983, pp. 349-365. doi:10.1111/j.1467-6486.1983.tb00212.x

[38] A. J. Shenhar and D. Dvir, "Toward a Typological Theory of Project Management," Research Policy, Vol. 25, No. 4, 1996, pp. 607-632. doi:10.1016/0048-7333(95)00877-2

[39] M. Alvesson and S. Sveningsson, "The Great Disappearing Act: Difficulties in Doing 'Leadership'," The Leadership Quarterly, Vol. 14, No. 3, 2003, pp. 359-381. doi:10.1016/S1048-9843(03)00031-6

[40] J. C. Flanagan, "The Critical Incident Technique," Psychological Bulletin, Vol. 51, No. 4, 1954, pp. 327-357.

[41] C. Besner and B. Hobbs, "Project Management Practice, Generic or Contextual: A Reality Check," Project Management Journal, Vol. 39, No. 1, 2008, pp. 16-33. doi:10.1002/pmj.20033

[42] A. L. Strauss and J. Corbin, "Basics of Qualitative Research: Techniques and Procedures for Developing Grounded Theory," 2nd Edition, Sage, Thousand Oaks, 1998.

[43] M. B. Miles and A. M. Huberman, "Qualitative Data Analysis: An Expanded Sourcebook," Sage, Thousand Oaks, 1994.

[44] K. Locke, "Grounded Theory in Management Research," Sage, London, 2001.

[45] K. M. Eisenhardt, "Making Fast Strategic Decisions in High-Velocity Environments," Academy of Management Journal, Vol. 32, No. 3, 1989, pp. 543-576. 


\section{doi: $10.2307 / 256434$}

[46] G. Grabher, "Temporary Architectures of Learning: Knowledge Governance in Project Ecologies," Organization Studies, Vol. 25, No. 9, 2004, pp. 1491-1514.

[47] R. A. Goodman and L. P. Goodman, "Some Management Issues in Temporary Systems: A Study of Professional Development and Manpower-The Theater Case," Administrative Science Quarterly, Vol. 21, No. 3, 1976, pp. 494-501. doi: $10.2307 / 2391857$

[48] C. Jones and B. Lichtenstein, "Temporary Inter-Organ- izational Projects: How Temporal and Social Embeddedness Enhance Coordination and Manage Uncertainty," In: S. Cropper, M. Ebers, C. Huxham and P. Smith Ring, Eds., The Oxford Handbook of Inter-Organizational Relations, Oxford University Press, Oxford, 2008, pp. 231255.

[49] M. I. Reed, "Organization, Trust and Control: A Realist Analysis," Organization Studies, Vol. 22, No. 2, 2001, pp. 201-228. doi:10.1177/0170840601222002

\section{Appendix}

Repertoires of practices and associated activities shaping project management.

\begin{tabular}{lll}
\hline Domain/practice & Activities shaping Practice & $\mathbf{N}$ \\
\hline
\end{tabular}

\section{Managing process}

1. Setting the pace

2. Taking action

3. Forecasting

4. Budgeting

\section{Managing people}

5. Communicating face-to-face

6. Giving responsibility

7. Team Building

\section{Managing the environment}

8. Representing

9. Politicking

\section{Managing information}

10. Integrating knowledge and information
Keeping time; Setting deadlines; Ensuring entrainment; Pacing; Timing; Thinking ahead

Making decisions, taking the plunge; Taking charge; Prioritising; Sanctioning; Ordering, Structuring; 60 Troubleshooting; Giving account; Keeping right direction; Keeping control; Keeping overview

Planning; scheduling

Guarding budget

Communicating transparently; Listening; Sensing; Meeting, consulting; Chairing Meetings

Delegating; Asking for help; Asking for input

Composing teams; Creating support; Joking; Motivating; Creating consensus; Pleasing; Creating commitment; Managing uncertainty/stress; Coaching; Managing conflict

Involving external parties; Making people available for project; Communicating externally; Creating 47 external support

Lobbying; Influencing; Carefully choosing key informants in Decision Making; Negotiating; Manipulating; Networking; Persuading 